Www.jmscr.igmpublication.org

Impact Factor (SJIF): 6.379

Index Copernicus Value: 79.54

ISSN (e)-2347-176x ISSN (p) 2455-0450

crossrefDOI: https://dx.doi.org/10.18535/jmscr/v6i11.96

Journal Of Medical Science And Clinical Research

\title{
Is Malnutrition Still a Serious Problem in India? A Comprehensive Review
}

\author{
Authors \\ Kishore Kumar Soni1 ${ }^{*}$, Aditya Banerjee ${ }^{2}$ \\ ${ }^{1,2}$ Department of Epidemiology, National Institute for Research in Environmental Health, \\ Indian Council of Medical Research, Bhopal (M.P.), India \\ *Corresponding Author \\ Kishore Kumar Soni \\ Email:k.soni2310@gmail.com
}

\begin{abstract}
Malnutrition is a leading cause of health-related distress in developing countries and is caused mainly due to protein-energy imbalance and deficiency of micronutrients. It can be a crucial risk factor of physical ailment and death around the globe. Every year thousands of people, including young children and pregnant females get affected .Protein-energy imbalance causes two of the most common types of malnutrition, namely, marasmus (simple starvation) and kwashiorkor (protein deficient diet). Characteristic manifestations of malnutrition in developing countries are seen due to deficiencies in micronutrients like iron, zinc, iodine and vitamin A. If poor diet along with infectious disease is highly prevalent at a regular interval, it results into a vicious impact. Although better diagnosis and treatment for malnutrition have been developed recently, patients belonging to rural areas have lesser access to such options due to minimal health service schemes. Strategies for preventing protein-energy imbalance range from promotion of breast-feeding to the use of food supplementations. Besides, micronutrient deficiencies can be addressed by planning strategies for a proper diet-plan. For example diversification of dietary materials using domestic gardens and livestock. Use of iodized salt is a great success globally, but supplementation of other nutrients is yet to cover vulnerable communities properly. For implementation of these strategies effectively, nutrition related educational campaigns and proper healthcare initiatives must be taken into stride. To eradicate malnutrition related problems, we must address poverty, which is clearly associated with the scarce supply of food and nutrition, educate people regarding the importance of nutrients in food, organize fundraisers and other programs to address the situation at hand, give extra attention to the extremely poverty stricken regions within a country and prioritize malnutrition related diseases as much as infectious diseases so that they can be eradicated once and for all.
\end{abstract}

Keywords: Malnutrition, protein imbalance, micronutrients, nutrition, strategies.

\section{Background}

An adverse state of nutrition that is a result of deficiency, or excess, of energy, protein, macro and micronutrients causing quantitative alterations in our body in terms of its shape, size composition and function, that further can give rise to clinical outcomes, is called malnutrition ${ }^{(1)}$. Although in case of under-nutrition, this definition does not fit because there is absence of unintentional weight loss. The three characteristic primary syndromes 
of unintentional weight loss are starvation, sarcopenia and cachexia ${ }^{(2,3)}$. Protein-energy deficiency is the main cause behind starvation. Starvation can be reversed with help of adequate energy due to sufficient protein intake, and therein lies the main difference between it and other syndromes of unintentional weight loss ${ }^{(4)}$. In case of sarcopenia, the muscle mass gradually decreases and that is common with normal ageing process though investigations are going on for this ${ }^{(5-7)}$. Sarcopenia on the other hand can't be overcome just by a balanced diet as the loss of muscle mass is not dependent on energy balance ${ }^{(8,9)}$. Activity of proinflammatory cytokines generally cause cachexia at a time when the body is compromised due to chronic conditions like cancer, HIV-AIDS, heart failure, etc. Cachexia is defined as metabolic syndrome that gives rise to complexities like a loss of muscle mass with or without losing body fat $^{(10)}$. Malnutrition is classified on the basis of three factors; absence of nutrients in diet, the duration of it and also the age at which the individual started receiving this particular diet. Two major types of malnutrition classified till date has been further divided.

Deficiency in protein and energy balance characterizes malnutrition, which may result into hampering of various biological processes ${ }^{(13)}$. Food security is a concept that allows everyone access to safe, nutritionally sufficient, economically viable food that is in sync with the location and culture ${ }^{(15)}$. But it is widely accepted that food security is not only limited to sufficient energy intake but also requires proper balance of essential micronutrients in one's diet. In developing countries it has been observed that diets containing low levels of vitamin A, iron, and zinc shows increasing number of people suffering from micronutrient deficient malnutrition. Billions of people suffer from iron deficiency and over 100 million of all pre-school children suffer from vitamin A deficiency ${ }^{(17)}$, the latter being the main reason behind eyesight problems that may lead to blindness along with issues in conceiving and developmental delays as well. In a study, it was estimated that around $30 \%$ population of the developing countries are at high risk of suffering from zinc deficiency ${ }^{(18)}$.

\section{Factors affecting nutritional status in children}

Child mortality especially in young ones below five years of age crosses about ten and a half million per year worldwide with $98 \%$ of these deaths occurring in developing countries ${ }^{(52)}$. The below par status of child health is mainly due to diarrhea and respiratory distress that also retard the development of a child and can lead to fatal consequences. Some of the factors to be considered behind such grim conditions are improper or absence of sanitization, pre-natal deficiencies in the mother, lack of awareness in rural areas and absence of proper immunization protocols ${ }^{(53,54)}$. In a nutritional assessment study of children under five years in the Mbarali district of Tanzania, factors influencing nutritional status of the cohort were assessed. The following indices for nutritional status was analyzed following the WHO criterion; weight for age, height for age and weight for height. Chi-square test was performed to establish an association between factors that would affect the nutritional status. According to the results after assessing 160 under five children, $39.4 \%$ were seen to be underweight amongst which, $13.8 \%$ were not in good shape. $27.5 \%$ were wasted and $5 \%$ out of them were in serious conditions. $30.7 \%$ were stunted out of which again $5 \%$ were seriously stunted. $1.8 \%$ female children were severely undernourished as opposed to $3.1 \%$ of male children. No statistical significance was found out between mothers with primary education as their children were severely stunted. The study was important in indicating some measures that could be taken to decrease the burden of malnutrition in children, like, educating the families in low birth weight and frequency of feeding, encouraging practices of proper sanitation and food habits, etc. ${ }^{(55)}$. Maternal factors are crucial when it comes to the fight against malnutrition in children. If the mothers are too young to give birth then accidental pregnancies 
can lead to a child born underweight ${ }^{(56)}$. Also if the mothers had iodine deficiency then their child could be mentally retarded and show an overall decrease in development ${ }^{(57)}$.

\section{Role of immunity in malnutrition}

Malnutrition is difficult to treat because the manifestations of it doesn't really depend on any one cause and as age of an individual increases some syndromes of malnutrition may arise which weren't assessed when the person was young ${ }^{(58)}$. In undernourished infants in the first 1000 days poor nutritional status can lead to atrophy in thymic development along with discrepancy in growth of immune organs. Thymic size is one of the crucial indicators of malnutrition. Maternal malnutrition can also affect immune development in her offspring because of epigenetic modifications that are caused by adverse nutrient status and that get passed on to the child ${ }^{(59)}$. The impairment of immunity due to undernutrition was assessed via a randomized controlled trial in which the outcome of an elemental dietary regime was shown on diarrhea-malnutrition in Zambian children. At the beginning all 161 children had persistent diarrhea but when an elemental diet was provided with all macronutrients broken down into amino acids, oligosaccharides or simple lipids, the children survived with no sign of diarrhea but. Parasitic prevalence was decreased and the new diet somehow influenced the functional barrier of mucosa that was compromised due to poor nutritional status ${ }^{(60)}$. Recent studies have shown that re-nutrition and dietary interventions can greatly influence immune responses by treating the defects that was seen prior to treatment. For example, improved complement levels, microbicidal activity of neutrophils increase along with high production of cytokines by monocytes ${ }^{(61)}$. Therefore role of immunity is 2-fold as it is a consequence of inadequate diet and also increases mortality and morbidity that comes with increased rate of infections following malnutrition.

\section{Current Scenario of Malnutrition in India}

Life expectancy in India has increased, with infant mortality rate decreasing in last five decades ${ }^{(19)}$. There has been enormous progressin the socioeconomic as well as political scenario. With a secured place as a permanent member of the United Nations, India is also currently one of the countries in the world holding high stakes in the atomic energy division. But the picture changes when it comes to increased malnutrition in general public, especially children. With almost $16 \%$ of world population residing in India, a major portion of people suffer from deficiency of vitamins and essential micronutrients.

For maintaining the vital physiological functions of our body, trace amount of micronutrients are needed. From the point-of-view of priority, they can be introduced easily. But the facts are however very different. As a consequence, malnutrition due to micronutrient deficiency has been a major problem in India since decades. According to the recent data, micronutrient deficiencies are leading to high malnutrition seen in present times. Daily intake of micronutrients via foods that are consumed by over $70 \%$ of Indians has shown less than $50 \%$ RDA, which is far from satisfactory ${ }^{(20)}$. Daily more than 6000 children below the age of 5 die here and more than $50 \%$ of these deaths are caused by malnutrition propagated by the lack of vitamin A, iron, iodine, zinc and folic acid. More than $50 \%$ of preschoolers and their mothers display symptoms of subclinical vitamin A deficiency ${ }^{(21)}$. As per a national study, anemia occurrence among infants is high and among women it is above $50 \%{ }^{(22)}$. As iron deficiency takes some time to manifest into anemia, such data reflects the situation of iron deficiency in Indian population.

The result of malnutrition caused by micronutrient deficiency is higher rates of morbidity and mortality $^{(20)}$. A combination in deficiency of Vitamin A, iron and zinc pose for the second largest risk factor in the global disease profile; vitamin A deficiency led to 330,000 child deaths almost every year in India; 22,000 people 
comprising mainly of pregnant women, die every year due to severe anemia; 6.6 million children that are born every year are mentally impaired due to iodine deficiency leading to an overall reduction in intellectual capacity and neural tube defects are seen in about 200,000 babies each year due to folic acid deficiency as well. Micronutrient malnutrition therefore qualifies to be treated with top priority. For efficient mitigation programs to combat any disease, three essential components are needed: a particular goal, policies to enable things and wholesome strategy ${ }^{(23)}$. These in turn need the support by Research and Development program. According to the tenth Five Year Plan $(2002-2007)^{(24)}$, the Indian Government has set up the following objectives :

1. Eradication of vitamin A deficiency addressing a crucial public health issue.

2. Reducing prevalence of anemia by $25 \%$, with moderate and severe anemia getting down by $50 \%$ in children, adolescents, pregnant and lactating women.

3. Universal access to iodized salt should be prioritized.

4. Reduction in prevalence of IDD in the country to less than $10 \%$ by 2010 .

These targets indicate a well-defined goal helping in quick and efficient policy planning by the government. However, the effective strategy to successfully achieve what was to be done was lacking. The program did not have a sound plan for implementation and had a poor monitoring potential and therefore failed. Thus it can be concluded that programs that did not do well before 2002 was because of unclear goals and guidelines that didn't work out. But later despite clearer goals, the strategy barely specified the personnel assigned to overlook each department and also lacked sufficient contingency plans. A strong department to monitor and back up along with proper options for correction was imperative for positive results. Due to prioritization of communicable diseases and eradicating poliomyelitis the issue of micronutrient based malnutrition always got the least attention from authorities. Thus during the $10^{\text {th }}$ five year plan, the prevalence of anemia was higher and this was completely opposite of what was envisioned when the plans were drawn out. Due to this, despite India being the one of the first countries to start an anemia control program along with a vitamin-A supplementation in 1970, in present times the situation is dire. For almost two years now all the states in India have shown lesser availability of iron and folic acid tablet stock for pregnant women that clearly indicates that anemia contributes to $20 \%$ of maternal deaths every year. The most shocking part is how the Ministry of Health in the state department has endorsed these figures and still failed to utilize even $50 \%$ of funds made available to them under the National Rural Health Mission scheme. But now the government is showing commitment towards prioritizing and working toward resolving micronutrient malnutrition. Indian Micronutrient Investment Plan $^{(25)}$ for 2007-2011 has been proposed by the Micronutrient Initiative, an international NonGovernment Organization working in collaboration with the Government of India.

\section{Possible ways to tackle malnutrition:}

Absorbable micronutrients in food are considered the best means for preventing micronutrient deficiencies ${ }^{(26-29)}$. But some communities lack supply of foods high in nutrient due to many constraints andthat calls for specific preventive and curative interventions ${ }^{(30)}$.

Gradually there has been growing consensus on the importance of interventions that pay attention towards incorporating multiple micronutrient components to fight against malnutrition ${ }^{(28,31)}$. Appropriate formulations of such nutrients can only be developed keeping in mind the synergistic/antagonistic effects of these on each ${ }^{(32-42)}$. A special kind of intervention includes provision of fat-based spreads (e.g., peanut butter) and "sprinkles" that contain multiple micronutrients to be mixed with food. But the limitation of all these interventions (except dietary diversification) lie in the fact that plant 
components high in fibers and phytosterols are not being investigated, although they show potential cancer and cardiovascular disease preventing abilities.

Micronutrient supplementation is generally provided by the existing health services and can be taken orally or (more rarely) by injection with priority being given to vulnerable populations, such as pregnant women and children ${ }^{(43)}$. Supplementation is mandatory for cases when other approaches are too slow in treating a specific deficiency. Although some micronutrients have to be taken daily or weekly (e.g., iron and zinc), others are easily stored in the body and needs to be taken at an interval of months or years (e.g., vitamin A and iodine) ${ }^{(44)}$.

Diet-based strategies are probably the most promising approach to sustainably control micronutrient deficiencies. Dietary diversification has to be promoted through consumption of broad variety of foods, preferably from home-gardens and small livestock produce. Due to globalization and high consumerism agricultural requirements have increased with a slower progression in increase of crop growth. So to increase yield and feed everyone, fertilizers and harmful components are being used that generally pose health risks. Therefore organic farming is being increasingly becoming popular to overcome these issues as well as promotion of household grown crops and vegetables can deliver essential nutrients without the harmful ingredients. Households should be given a proper education as to how to increase production of dark-green leafy vegetables, yellow and orange fruits, poultry, eggs, fish and milk.

A probable future strategy to prevent micronutrient deficiencies is to breed micronutrient-rich crops, through either conventional breeding techniques or genetic modification of existing crops. But according to the Millennium Development Goals (MDGs) drawn up by the UN, that aims at alleviating all poverty and health related issues by 2015 , we are still not on track when it comes to overcoming micronutrient malnutrition $(\mathrm{MNM})^{(51)}$. Also the micronutrient

concentrations

achieved

implementing the above methods have been very low. For example, in case of vitamin A deficiency there is no knowledge regarding the amount of $\beta$ carotene available from the new "golden rice" and how much rice must be consumed to meet an individual's needs. Also iron concentration in bioengineered rice are hardly higher than those present in natural varieties such as basmati and jasmine rice ${ }^{(45)}$.

\section{Conclusion}

Malnutrition involves hampering the normal growth and development of an individual's body due to inefficient or excess dietary nutrients. It plagues populations of developing and third world countries where poverty is the number one reason for people not getting access to safe food and water sources. Its high time to address this dire problem and introduce programs and schemes that allow populations, mainly in rural areas to thrive towards not being underdeveloped. From the above figures we can say that countries like India has been hit hard by malnutrition but still it doesn't take it seriously due to corruption and political turbulence. Although many reasons have been attributed to the development and persistence of malnutrition, only holistic approaches from implementing multiple programs can combat it (46). A variety of actions are required that include agricultural and micronutrient interventions, provision of safe drinking water and sanitation, education regarding support for better diets, special attention to gender issues and vulnerable groups such as pregnant women and young children, and quality of health services ${ }^{(47)}$. In case of rural populations, though rules and regulations are available on how to manage malnutrition and diseases related to it, lack of education and ageold practices along with social and economic taboo that covet many issues decelerate the rate of progress that is actually becoming quite evident from the current disappointing facts and figures. Educating the locals about protein-rich and micronutrient rich sources from plants that are 
available around can be very effective ${ }^{(48,49)}$. For example, avocado is becoming very popular recently due to content of vitamins $\mathrm{C}, \mathrm{E}$ and $\mathrm{B} 6$ along with anti-oxidants. But it is expensive and not available for the section of society that we are addressing. Some other important and easily available plant based foods can be beetroot which is high in calcium and magnesium along with millets with a high protein content.

Eight developmental goals were planned for execution by 147 heads of State at the United Nations Millennium Summit in 2000. The goal on hunger was directed towards reducing extreme poverty and starvation by the year 2015 by half in reference to the 1990 figures, ${ }^{(50)}$ but progress toward the other 7 goals (universal primary education; empowering women; improvement in maternal health; decreased child mortality; advances in preventing and managing HIV/ AIDS, malaria and other diseases; environmental protection; and global partnerships aimed at development) had directly and indirectly contributed in reducing malnutrition in developing countries.

\section{References}

1. Stratton RJ, Green CJ, Elia M (2003). "Scientific criteria for defining malnutrition Disease-Related Malnutrition. An Evidence Based Approach to Treatment" CABI Publishing Wallingford.

2. Chapman IM (2011). "Weight loss in older persons". Medical Clinics of North America. 95: 579-93.

3. Thomas D (2007). "Loss of skeletal muscle mass in aging: examining the relationship of starvation sarcopenia and cachexia". Clinical Nutr. 26: 389-99.

4. Thomas D (2002). "Distinguishing starvation from cachexia". Clinics in Geriatric Medicine 18: 883-91.

5. Cruz-Jentoft AJ, Baeyens JP, Bauer JM, Boirie Y, Cederholm T, et al. (2010). "Sarcopenia: European consensus on definition and diagnosis: report of the
European Working Group on sarcopenia in older people". Age and Ageing. 39: 41223.

6. Fielding RA, Vellas B, Evans WJ, Bhasin S, Morley JE, et al. (2011). "Sarcopenia: an undiagnosed condition in older adults. Current consensus definition: prevalence, etiology and consequences. International Working Group on Sarcopenia”. J of the American Med Directors Association. 12: 249-56.

7. Muscaritoli M, Anker SD, Argilés J, Aversa Z, Bauer JM, et al. (2010). "Consensus definition of sarcopenia cachexia and pre-cachexia: joint document elaborated by Special Interest Groups (SIG) 'cachexia-anorexia in chronic wasting diseases' and 'nutrition in geriatric"”. Clinical Nutr. 29: 154-9.

8. Messinger-Rapport B, Thomas D, Gammack J, Morley J (2009). "Clinical update on nursing home medicine". $J$ of the American Medical Directors Association. 10: 530-53.

9. Rolland Y, Dupuy C, van Kan GA, Gillette S, Vellas B (2011). "Treatment strategies for sarcopenia and frailty". Medical Clinics of North America. 95: 427-38.

10. Evans WJ, Morley JE, Argilés J, Bales C, Baracos V, et al. (2008). "Cachexia: a new definition”. Clinical Nutr. 27: 793-9.

11. Bertini C (2006). Report of the Standing Committee on Nutrition at its 33rd Session Hosted by the World Health Organization Geneva Switzerland. Available from http://www.foodfirstnl.ca/what-is-foodsecurity/

12. United Nations Standing Committee on Nutrition (2005). Fifth report on the world nutrition situation: nutrition for improved development outcomes Geneva.

13. Hotz C, Brown K (2004). Assessment of the risk of zinc deficiency in populations and options for its control: International 
Zinc Nutrition Consultative Group Technical Document Available from: http://www.Indiahealthstat.com./Indi a/showdata.

14. National Nutrition Monitoring Beurau. (2002). Hyderabad: National Institute of Nutrition.

15. Controlling Vitamins and Mineral Deficiency in India Meeting the Goal (2007). Micronutrient Initiative.

16. National Family Health Survey (20052006). Mumbai: International Institute of Population Science; 2007.

17. Rip Y. (2002). "Prevention and control of iron deficiency: Policy and strategy issues". J Nutr.132 :802S-S.

18. Tenth Five Year Plan, Planning Commission, Government of India. 2002

19. Indra micronutriment health services to improve nutrition in young children: a cluster-randomised controlled trial. Lancet. 365:1863-72. inversement plan (20072011). Micronutriment Initiative. 2007 Available from https://www.huffingtonpost.com.au/2017/0 8/20/8-easy-ways-to-boost-nutrientabsorption_a_23079874/

20. Gibson RS, Yeudall F, Drost N, Mtitimuni B, Cullinan T. (1998). Dietary interventions to prevent zinc deficiency. Am $J$ ClinNutr. 68(2 Suppl): 484S-7S.

21. Tontisirin K, Nantel G, Bhattacharjee L. (2002) Food-based strategies to meet the challenges of micronutrient malnutrition in the developing world. ProcNutr Soc. 61: 243-50.

22. International Zinc Nutrition Consultative Group. (2004) Assessment of the risk of zinc deficiency in populations and options for its control. Food Nutr Bull. 25: S91204.

23. 114. Holmes W, Toole M. (2005). Micronutrient supplements in pregnant Nepalese women. Lancet. 365: 916-7.
24. Shrimpton R, Gross R, Darnton-Hill I, Young M. (2005) Zinc deficiency: What are the most appropriate interventions? BMJ. 330: 347-9.

25. Baly DL, Golub MS, Gershwin ME, Hurley LS. (1984) Studies of marginal zinc deprivation in rhesus monkeys. 3 . Effects of vitamin A metabolism. Am J ClinNutr. 40: 199-207.

26. Bloem MW, Wedel M, van Agtmaal EJ, Speek AJ, Saowakontha S, Schreurs WH. (1990). Vitamin A intervention: short-term effects of a single, oral, massive dose on iron metabolism. Am J ClinNutr. 51:76-9.

27. Allen LH. (1998). Zinc and micronutrient supplements for children [review]. Am J ClinNutr. 68 (2 Suppl): 495S-8S.

28. Christian P, West KP Jr. (1998) Interactions between zinc and vitamin $\mathrm{A}$ : an update. Am J ClinNutr. 68 (2 Suppl): 435S-41S.

29. 36. Gibson RS. (2000) Zinc supplementation for infants. Lancet. 355: 2008-9.

30. Rahman MM, Vermund SH, Wahed MA, Fuchs GJ, Baqui AH, Alvarez JO. (2001). Simultaneous zinc and vitamin A supplementation in Bangladeshi children: randomised double blind controlled trial. BMJ. 323: 314-8.

31. Zimmermann MB, Zeder C, Chaouki N, Torresani T, Saad A, Hurrell RF. (2002). Addition of microencapsulated iron to iodized salt improves the efficacy of iodine in goitrous, iron-deficient children: a randomized, double-blind, controlled trial. Eur J Endocrinol. 147:747-53.

32. Zimmermann MB, Zeder C, Chaouki N, Saad A, Torresani T, Hurrell RF. (2003). Dual fortification of salt with iodine and microencapsulated iron: a randomized, double-blind, controlled trial in Moroccan schoolchildren. Am J ClinNutr. 77:42532. 
33. Zimmermann MB, Wegmueller R, Zeder C, Chaouki N, Biebinger R, Hurrell RF, et al. (2004). Triple fortification of salt with microcapsules of iodine, iron, and vitamin A. Am J ClinNutr. 80:1283-90.

34. Hurrell RF, Lynch S, Bothwell T, Cori H, Glahn R, Hertrampf E, et al. (2004). Enhancing the absorption of fortification iron. A SUSTAIN Task Force report [review]. Int J VitamNutr Res. 74:387-401.

35. Osrin D, Vaidya A, Shrestha Y, Baniya RB, Manandahar DS, Adhikari RK, et al. (2005). Effects of antenatal multiple micronutrient supplementation on birthweight and gestational duration in Nepal: double-blind, randomised controlled trial. Lancet. 365: 955-62.

36. Osrin D, Vaidya A, Shrestha Y, Baniya RB, Manandahar DS, Adhikari RK, et al. (2005). Effects of antenatal multiple micronutrient supplementation on birthweight and gestational duration in Nepal: double-blind, randomised controlled trial. Lancet. 365: 955-62.

37. Siddiqui IA, Rahman MA, Jaleel A. (2004). Efficacy of daily vs. weekly supplementation of iron in schoolchildren with low iron status. J Trop Pediatr. 50: 276-8.

38. Gregorio GB. (2002). Progress in breeding for trace minerals in staple crops. $J$ Nutr. 132: 500S-2S.

39. Bhargava A. (2001). Commission on Macroeconomics and Health. Nutrition, health, and economic development: some policy priorities. $\mathrm{CMH}$ working paper no. Geneva: World Health Organization.

40. Victora CG, Hanson K, Bryce J, Vaughan P. (2004). Achieving universal coverage with health interventions. Lancet. 364: 1541-8.

41. Penny ME, Creed-Kanashiro HM, Robert RC, Narro MR, Caulfield LE, Black RE. (2005). Effectiveness of an educational intervention delivered through the
42. Dewey KG. (2005). Infant nutrition in developing countries: What works? Lancet. 365:1832-

43. UN Millennium Project Task Force on Hunger. (2005). Halving hunger: it can be done. Sterling (VA): Earthscan.

44. Mayer JE, Pfeiffer WH, Beyer P. Biofortified crops to alleviate micronutrient malnutrition. Current opinion in plant biology. 2008 Apr 1;11(2):166-70.

45. UNICEF. United Nations Children's Fund, The state of the world's children 2006.

46. Pal S. An analysis of childhood malnutrition in rural India: role of gender, income and other household characteristics. World Development. 1999 Jul 1;27(7):1151-71.

47. Solar O, Irwin A. Social determinants, political contexts and civil society action: a historical perspective on the Commission on Social Determinants of Health. Health Promotion Journal of Australia. 2006;17(3):180-5185.

48. Malambugi TR. Factors influencing nutritional status of children below five years in Mbarali district, Mbeya region, Tanzania (Doctoral dissertation, Sokoineuniversity of agriculture.).

49. Dewan M. Malnutrition in women. Studies on Home and Community Science. 2008 Jul 1;2(1):7-10.

50. UNICEF. Micronutrients-Iodine, Iron and Vitamin A.

51. Bourke CD, Berkley JA, Prendergast AJ. Immune dysfunction as a cause and consequence of malnutrition. Trends in immunology. 2016 Jun 1;37(6):386-98.

52. Cooper WN, Khulan B, Owens S, Elks CE, Seidel V, Prentice AM, Belteki G, Ong KK, Affara NA, Constância M, Dunger DB. DNA methylation profiling at imprinted loci after periconceptional micronutrient supplementation in humans: results of a pilot randomized controlled 
trial. The FASEB Journal. 2012 May;26(5):1782-90.

53. Amadi B, Mwiya M, Chomba E, Thomson M, Chintu C, Kelly P, Walker-Smith J. Improved nutritional recovery on an elemental diet in Zambian children with persistent diarrhoea and malnutrition. Journal of tropical pediatrics. 2005 Feb 1;51(1):5-10.

54. Vásquez-Garibay E, Campollo-Rivas O, Romero-Velarde E, Méndez-Estrada C, García-Iglesias T, Alvizo-Mora JG, Vizmanos-Lamotte B. Effect of renutrition on natural and cell-mediated immune response in infants with severe malnutrition. Journal of pediatric gastroenterology and nutrition. 2002 Mar 1;34(3):296-301. 